\title{
Inúmeros desafios do passado proporcionam aos portadores de HIV o largo acesso aos antirretrovirais no presente
}

CORREAA, Marilena; CASSIER, Maurice.

Aids e saúde pública: contribuiçôes à reflexão sobre uma nova economia política dos medicamentos no Brasil.

Rio de Janeiro: EdUERJ, 2010. 244 p.

\section{| ${ }^{1}$ Sarah Kitchenman |}

${ }^{1}$ Enfermeira, mestre em Saúde Coletiva pelo IMS-UERJ. Endereço eletrônico: skitchenman@yahoo.com.br

O livro, dividido em seis capítulos, foi organizado por Marilena Corrêa e Maurice Cassier. Tendo como uma de suas propostas analisar diferentes aspectos da luta contra a epidemia de Aids, foi escrito por diversos autores que tratam de temas como desafios nacionais e internacionais enfrentados na fabricação dos antirretrovirais, abertura da indústria farmacêutica nacional, Aids como questão de saúde pública, lei de propriedade intelectual, dentre outros. Foi publicado em 2010 e realizado por instituições acadêmicas brasileiras e francesas. São elas: o Instituto de Medicina Social da Universidade do Estado do Rio de Janeiro (IMSUERJ), o Instituto de Tecnologia de Fármacos (Manguinhos) da Fundação Oswaldo Cruz (Fiocruz) e o Centre de Recherche, Médicine, Sciences, Santé, Santé Mentale et Societé (Cermes).

No primeiro capítulo, a autora Maria Andrea Loyola nos mostra todo o processo e entraves da entrada dos medicamentos genéricos no Brasil. A vontade política de governantes e a participação de atores sociais, em sua maioria atuantes do movimento sanitário brasileiro, foram indispensáveis à abertura da indústria farmacêutica nacional. Através deste apoio, as indústrias passaram a fabricar os próprios medicamentos, tornando-se menos dependentes do mercado internacional de medicamentos. A autora também nos apresenta a história das indústrias farmacêuticas nacionais e conta como ocorreram a pressão e a opressão das empresas estrangeiras sobre as empresas nacionais da área farmacêutica. 
Através das dificuldades e entraves ao desenvolvimento tecnológico local criado pelas multinacionais, estas perpetuariam o domínio e a dependência tecnológica do Brasil e demais países periféricos.

Segundo a autora, somente nos anos 1980 se pôde dizer que esta situação começou a mudar. Surgiram a Nortec e a Labgen, que se tornaram novas produtoras de fármacos e matérias-primas locais. Os laboratórios públicos foram reestruturados, bem como o Farmanguinhos, que foi um dos principais laboratórios públicos do país, pois desempenhou papel crucial na produção dos genéricos no país. Pode-se dizer que essa conquista foi proveniente de esforços de pessoas e grupos de combate à Aids que buscaram, na Constituição Federal, o direito ao acesso gratuito aos fármacos necessários para o tratamento da Aids. É importante ressaltar que essa proposta só foi possível a partir da implementação da Lei dos Genéricos.

No segundo capítulo, os autores tratam da Lei dos Genéricos no Brasil, bem como da batalha que se estabeleceu entre os laboratórios internacionais e o governo brasileiro. Os autores destacam também a importante atuação da mídia diante deste fato. Em 2001, mesmo com toda insatisfação do setor farmacêutico, o governo brasileiro, através do congelamento dos preços e do estímulo à comercialização dos genéricos, estabeleceu a regulamentação do mercado de medicamentos. Diante desta situação, mesmo contra as diligências da Organização Mundial do Comércio (OMC), passou-se a produzir genéricos dos antirretrovirais no Brasil. Em contrapartida, os laboratórios internacionais, principalmente os norte-americanos, defendiam a proteção intelectual e as patentes dos antirretrovirais, no sentido de incentivar o desenvolvimento de medicamentos através dos lucros das empresas advindos da própria venda de suas invenções. Neste sentido, a cópia de medicamentos (como consideram os genéricos) traria prejuízos à pesquisa e ao desenvolvimento de novas invenções.

Cabe ressaltar que a quebra de patentes e a produção dos genéricos no Brasil foram igualmente importantes para países mais pobres, que, desprovidos de poder político, não conseguiam negociar à altura dos laboratórios internacionais e demais governos. A mídia teve ampla participação ao longo dessa importante questão social e política, sendo responsável pela divulgação, problematização e politização. Da mesma forma, ajudou a encaminhar questôes de saúde pública, trazendo e levando informações tanto aos especialistas quanto aos leigos. 
No capítulo três, o autor destaca os debates sobre propriedade intelectual que ganharam maior amplitude no ano de 2001. As antigas questóes das patentes (abordadas no capítulo anterior) haviam sido gradualmente construídas como um problema de saúde pública; assim, a Política Nacional de DST/Aids, como um programa de saúde pública, dependia essencialmente da produção de genéricos para a continuidade do tratamento dos portadores de HIV/Aids. A impossibilidade da fabricação significaria estar à mercê dos preços de mercado internacional, bem como das flutuações cambiais e da tecnologia estrangeira.

Foi somente na Declaração de Doha que ficou estabelecida a prioridade da saúde pública e humanitária em detrimento das questôes de direito de propriedade intelectual relativas ao comércio. Após esta conquista, o laboratório indiano passou a fabricar genéricos e oferecê-los a preços significantemente menores que os Estados Unidos e Europa. Cabe lembrar que a Organização dos Médicos sem Fronteiras (MSF) engajou-se intensamente na luta contra a Aids. E por este motivo, a organização passou a lutar pela quebra de patentes que viabilizasse o direito de produzir os genéricos dos ARVs localmente e sobretudo nos países mais pobres. Com o incentivo da MSF, as ONGs brasileiras passaram a se envolver com o tema da propriedade intelectual, razão pela qual o governo brasileiro estava impossibilitado de fabricar os genéricos dos ARVs.

Em oposição à lei de propriedade intelectual, foi criado o Grupo de Trabalho de Propriedade Intelectual (GTPI), composto por diversas ONGs e organizações internacionais. Tinha como meta acompanhar questôes relacionadas à propriedade intelectual, pressionar e sensibilizar autoridades em causa da vida. Um dos objetivos da MSF, GTPI e outras organizaçôes ligadas à luta contra a Aids era difundir informações sobretudo para pessoas com menos recursos e que nos últimos anos haviam sido fortemente atingidas pela epidemia. Estimularam a adesão dos pacientes ao tratamento, fiscalizaram e acompanharam testes de novas drogas, reivindicaram ética e responsabilidade nas pesquisas com seres humanos, e posteriormente lutaram pela licença compulsória de novas drogas que surgiram.

As autoras iniciam o quarto capítulo destacando que o processo de patenteamento na área farmacêutica ocorreu tardiamente em quase todo o mundo. E discute como as políticas públicas atuaram na produção local dos medicamentos. A partir de 1996, com o sucesso das terapias contra o HIV, essa doença tomava novos rumos. Os países buscavam obter, através da compra ou 
1246 fabricação local, as drogas capazes de garantir a saúde dos portadores do vírus. Com este intuito, Farmanguinhos passou a produzir esses medicamentos, além de difundir conhecimentos técnicos a outros laboratórios. Ao mesmo tempo, o Estado, apostando no desenvolvimento local de tecnologias, favoreceu a criação de muitas empresas farmacêuticas no Brasil, além de apoiar seu desenvolvimento através de estratégias. Infelizmente, nota-se que tal apoio cessou no momento em que entrou em vigor o novo Estatuto de Propriedade Industrial de Medicamentos.

As críticas internacionais apontavam o Brasil como responsável pela pirataria dos ARVs e consequente desperdício do plano de pesquisa e desenvolvimento $(\mathrm{P} \& \mathrm{D})$. Entretanto, esta acusação era falsa, pois na verdade as cópias dos medicamentos que o Brasil desenvolveu foram lícitas, pois se tratava de ARVs anteriores a 1997 - portanto, antes ds Lei de Propriedade Industrial. Ao contrário dos argumentos utilizados a favor do plano de P\&D, observou-se que os esforços na fabricação local de ARVs trouxeram ao país um alto aprendizado tecnológico. Além disso, a engenharia reversa utilizada no Brasil para a produção local dos ARVs não pôde ser considerada uma simples cópia, pois para sua realização foi necessário inovar, melhorando os processos de produção e trazendo pesquisa e desenvolvimento para laboratórios públicos e privados do país.

No capítulo cinco, percebe-se que o advento do acordo Trips (sobre aspectos do direito de propriedade industrial ao comércio) e a Lei de Propriedade Industrial de 1996 fizeram com que o Brasil necessitasse de formas para desenvolver suas próprias patentes. Por isso, no que tange aos produtos farmacêuticos, foi criada a anuência prévia, um exame que leva em conta questôes de saúde pública, bem como os requisitos necessários para a patente, a saber: novidade, atividade inventiva e aplicação industrial. Através da anuência prévia, a patenteabilidade de medicamentos passou a ser discutida no âmbito do acesso à saúde, sendo capaz de produzir um controle mais criterioso para a concessão de patentes dos produtos farmacêuticos.

Uma questão polêmica no cenário das patentes de medicamentos é a patente de segundo uso médico: trata-se de moléculas já conhecidas, mas com novo uso terapêutico. Observa-se que as patentes devem ser criteriosamente avaliadas, visto que sua concessão implica diretamente no preço e acesso ao produto farmacêutico.

No último capítulo, a autora nos lembra das consequências negativas do acordo Trips para os países com pouca ou nenhuma tecnologia. Esses países 
encontraram dificuldade para lançar suas próprias tecnologias devido a um atraso constituído ao longo da história. Com isso, foram obrigados a aceitar preços e condições muitas vezes inviáveis para adquirir um medicamento ou equipamento de saúde. Neste sentido, a autora defende que as tecnologias desenvolvidas no Brasil devem ser patenteadas, ressaltando, entretanto, o cuidado que se deve tomar com as patentes consideradas frívolas, ou seja, aquelas que não são invenção e contrariam a Lei de Propriedade Intelectual (LPI). Nesta avaliação, desenvolveuse o subsídio para o exame, que é um julgamento utilizado como salvaguarda para os examinadores que utilizam esta ferramenta no sentido de garantir o nãopatenteamento aos produtos considerados não-patenteáveis.

O livro salienta, ao longo dos seis capítulos, a forte tensão que ocorreu entre o direito de propriedade industrial farmacêutica internacional, as ações relacionadas à Aids e a fabricação dos antirretrovirais, bem como a questão das patentes como assunto de saúde publica. Pode-se dizer que a fabricação dos genéricos dos ARVs no Brasil trouxe esperança de vida a muitos portadores do vírus HIV. Da mesma forma, produziu um alto aprendizado tecnológico necessário para o futuro desenvolvimento de demais medicamentos. Destaca-se, portanto, a importância dessa medida, que não somente beneficiou os portadores de HIV/Aids mas também portadores de outras doenças.

Além disso, nota-se que a fabricação local dos genéricos reduziu enormemente o preço de diversos medicamentos, possibilitou o desenvolvimento de programas de farmácia popular e permitiu a distribuição gratuita de medicamentos nos serviços públicos de saúde. Foi através dessas experiências que os laboratórios brasileiros se tornaram capazes de produzir aprendizado tecnológico próprio e desenvolver novas associações moleculares, rotas de síntese e formulação de novos medicamentos. Tais inovações não ficaram somente no nível local, mas se estenderam a outros países.

Ainda é difícil definir até que ponto se deve defender a lei de propriedade de um medicamento ou beneficiar o bem-estar da população. Essas leis foram criadas para retroalimentar economicamente os fabricantes e fomentar novas pesquisas, ao mesmo tempo em que a linha entre a economia e saúde às vezes ultrapassa fronteiras geopolíticas muito mais amplas e antigas. Desta forma, pode-se dizer que o presente livro amplia conhecimentos acerca do contexto que envolveu as políticas de desenvolvimento de medicamentos antirretrovirais no 
1248 Brasil e no mundo, discutindo os embates mundiais travados nesta batalha, além de trazer informações acerca da concessão de patentes em território nacional.

As contribuições dos autores por vezes se tornam semelhantes, pois algumas das informaçōes se entrecruzam ao longo dos capítulos. Recomenda-se a leitura desta obra, publicada no ano de 2010, na medida em que ela colabora com a reflexão de temas políticos e éticos que envolvem a lei de propriedade intelectual versus Aids como questão de saúde pública. 